\title{
Combustion Model and Control Parameter Optimization Methods for Single Cylinder Diesel Engine
}

\author{
Bambang Wahono' ${ }^{1}$ and Harutoshi Ogai ${ }^{2}$ \\ ${ }^{1}$ Research Centre for Electrical Power \& Mechatronics, Indonesian Institute of Sciences, Komp LIPI Jl Cisitu 21/54D, Gd 20, \\ Bandung 40135, Indonesia \\ ${ }^{2}$ Graduate School of Information, Production and Systems, Waseda University, 2-7 Hibikino, Wakamatsu-ku, Kitakyushu, \\ Fukuoka 808-0135, Japan
}

Correspondence should be addressed to Bambang Wahono; bambangwahono80@yahoo.co.id

Received 26 May 2014; Accepted 2 September 2014; Published 22 September 2014

Academic Editor: Cheng-Hong Yang

Copyright (c) 2014 B. Wahono and H. Ogai. This is an open access article distributed under the Creative Commons Attribution License, which permits unrestricted use, distribution, and reproduction in any medium, provided the original work is properly cited.

\begin{abstract}
This research presents a method to construct a combustion model and a method to optimize some control parameters of diesel engine in order to develop a model-based control system. The construction purpose of the model is to appropriately manage some control parameters to obtain the values of fuel consumption and emission as the engine output objectives. Stepwise method considering multicollinearity was applied to construct combustion model with the polynomial model. Using the experimental data of a single cylinder diesel engine, the model of power, $\mathrm{BSFC}, \mathrm{NO}_{x}$, and soot on multiple injection diesel engines was built. The proposed method succesfully developed the model that describes control parameters in relation to the engine outputs. Although many control devices can be mounted to diesel engine, optimization technique is required to utilize this method in finding optimal engine operating conditions efficiently beside the existing development of individual emission control methods. Particle swarm optimization (PSO) was used to calculate control parameters to optimize fuel consumption and emission based on the model. The proposed method is able to calculate control parameters efficiently to optimize evaluation item based on the model. Finally, the model which added PSO then was compiled in a microcontroller.
\end{abstract}

\section{Introduction}

Currently, energy and environmental pollution have become hot topics. Public and private transportations system plays an important role in people's life. Vehicle has become one of the most important factors in this system. In Jakarta, it is reported that $70 \%$ exhaust gas pollution is from vehicles [1].

Internal combustion engine is the main power of the vehicle. The global challenge in internal combustion engine is the reduction of exhaust gas such as soot, $\mathrm{NO}_{x}[2,3], \mathrm{CO}$, $\mathrm{HC}$, and particulate matter (PM) emissions from vehicles by improving fuel consumption without sacrificing the vehicle performance. On the other side, most internal combustion engine methods that reduce either $\mathrm{NO}_{x}$ or soot emissions cause an increase in the other emissions [4]. Recently, with the environmental restrictions and sustainable development, pollution standards have been more and more stringent. For example, in Japan, the standard of diesel engine emission regulation is very high. In 2003 the MOE finalized very stringent 2005 emission standards for both light and heavy vehicles although it remained relaxed through the 1990s. In 2005 heavy-duty emission standards $\left(\mathrm{NO}_{x}=2 \mathrm{~g} / \mathrm{kWh}\right.$, $\mathrm{PM}=0.027 \mathrm{~g} / \mathrm{kWh}$ ) were the most stringent diesel emission regulations in the world. In 2009, this standards were more tightened $\left(\mathrm{NO}_{x}=0.7 \mathrm{~g} / \mathrm{kWh}, \mathrm{PM}=0.01 \mathrm{~g} / \mathrm{kWh}\right)$ to a level in-between the US 2010 and Euro V requirements [5]. So engine pollutant emission reduction became a major interest for engine development.

Additionally, a technology to decrease the exhaust gas emission often increases brake specific fuel consumption (BSFC) and causes deprivation in fuel economy, which in turn increases the emissions of $\mathrm{CO}_{2}$. Thus, it is of importance to reduce the emissions while improving BSFC. 
There are some methods that have been proposed to reduce diesel engine exhaust gas emissions. One of them is method for in-cylinder control, that is, exhaust gas recirculation (EGR) which can reduce $\mathrm{NO}_{x}$ emissions by reducing the combustion temperatures $[6,7]$. The other method is ultrahigh injection pressure which can reduce soot emissions [8]. However, due to high combustion temperatures associated with high injection pressures, $\mathrm{NO}_{x}$ emissions are likely to increase.

The current diesel engine has been equipped with a number of control devices such as multiple injection equipment with common-rail system and turbocharger [9]. Appropriate configurations of multiple injections can reduce soot emissions without a significant increase in $\mathrm{NO}_{x}$ emissions [10].

The previous methods individually have been proven to work toward the reduction of a particular pollutant. Evaluation of combinations of these methods, however, is a heavy task considering the total number of experiments that need to be performed.

Although many control devices can be mounted in diesel engine, a technology which sets the multiple control parameter of these control devices optimally is needed. In order to control the large number of control parameters appropriately by considering the fuel consumption and exhaust gas components as the engine output objectives, a combustion model construction which reproduces the characteristic value of fuel consumption and exhaust gas components from control parameter is needed. In order to know the characteristics of the combustion, the construction of a combustion model to reproduce the characteristic values of fuel consumption and exhaust gas components from the control parameters is called for. Furthermore, in order to improve the fuel efficiency and to reduce the exhaust gas emission, the control parameter optimization is needed.

This research has target to construct a combustion model, to get the optimal control parameter, and to validate in the real diesel engine experimental device. In this study, we applied the stepwise method considering multicollinearity to construct a combustion model. In the construction of a combustion model, the method of approximating by a polynomial model based on experimental data was used. We used the experimental data of single cylinder diesel engine to build a predictive model of fuel consumption and exhaust gas in multiple injections. Furthermore, PSO (particle swarm optimization) method was used to optimize the control parameters and validated in diesel engine. Finally, we evaluated its performance with validation in diesel engine.

\section{Methodology}

To increase the fuel efficiency and decrease exhaust emission, diesel engine optimization on model-based control system is proposed. In model-based control system, engine conditions are directly calculated by models, which achieve a time benefit and improve accuracy in comparison with conventional maps.

The methodology of this research consists of several steps. First, we get the data from the diesel engine laboratory to build the combustion model. Second, we build the combustion model by stepwise method considering multicollinearity using diesel engine data. Third, we get the optimal value of control parameter by the PSO. Fourth, we validate the control performance in diesel engine laboratory. Finally, we compile the combustion model which added PSO in a microcontroller, and control performance is evaluated. For more details, we can see the schematic of diesel engine system in Figure 1.

\section{Single Cylinder Diesel Engine Experiment}

3.1. Specification of Diesel Engine. In this research, we developed an experimental device for studying the control technology to improve the fuel consumption and reduce the diesel engine emission. The diesel engine experimental device is in Figure 2.

In this research, we choose a four-cycle one-cylinder diesel engine. This research used Yanmar TF70 V-E diesel engine with 4 cycle horizontal type water-cooling and equipped with a turbocharger (in Figure 2). The specification of single cylinder diesel engine is as in Table 1.

3.2. Experiment Condition of Multistage Injection Diesel Engine. In this research, the diesel engine is set with three stage injection, that is, pilot 1 injection, pilot 2 injection, and main injection as shown in Figure 3. Then, the rotation speeds were $1000 \mathrm{rpm}, 1500 \mathrm{rpm}$, and $2000 \mathrm{rpm}$; EGR rate was $0 \%$ and the engine temperature was set at about $90^{\circ} \mathrm{C}$ degrees. The engine control parameters were set as in Table 2 and the engine optimization objectives are listed as in Table 3.

The experiment was done under the condition mentioned above and the experiment results will be discussed in the next part.

\section{Stepwise Method Considering Multicollinearity}

4.1. Stepwise Method. Stepwise method is a systematic method for adding and removing terms from a multilinear model based on their statistical significance in a regression [11]. It uses statistical methods to remove the redundant variables. In this study, it is to identify good model with considerably less computing than is required for all possible regressions. The main approaches in this method are forward selection, backward elimination, and bidirectional elimination. Forward selection is as follows: starting with no variables in the model, testing the addition of each variable using a chosen model comparison criterion, adding the variable that improves the model the most, and repeating this process until none improves the model. Backward elimination is as follows: starting with all candidate variables, testing the deletion of each variable using a chosen model comparison criterion, deleting the variable that improves the model the most by being deleted, and repeating this process until no further improvement is possible. Bidirectional elimination is as follows: a combination of the above, testing at each step 


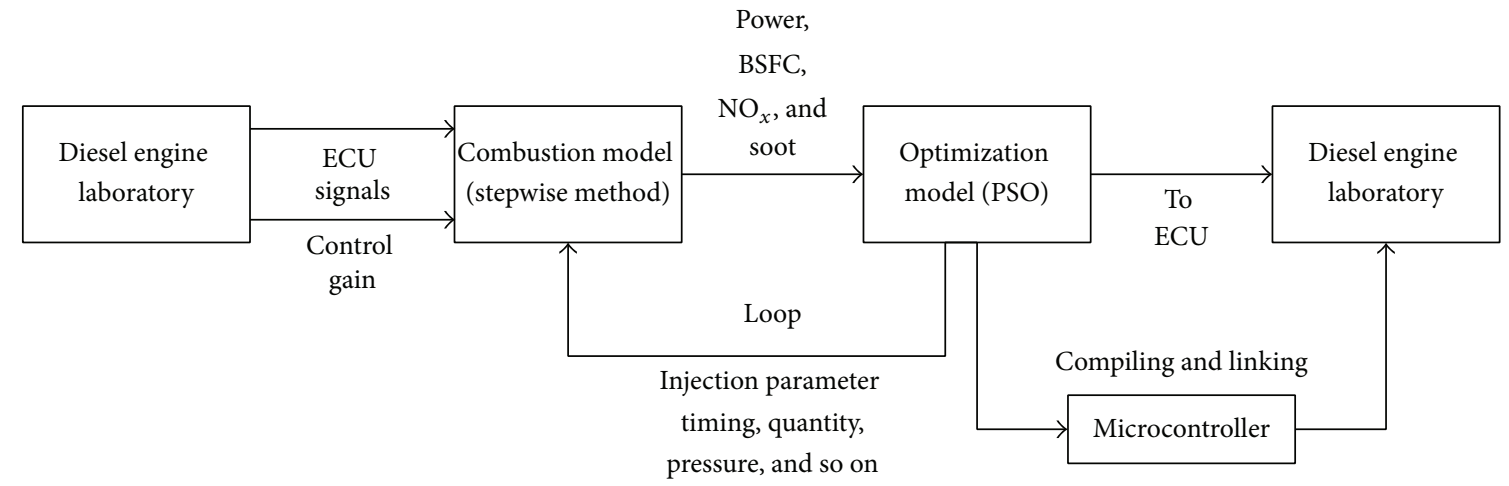

Figure 1: Schematic of diesel engine system.

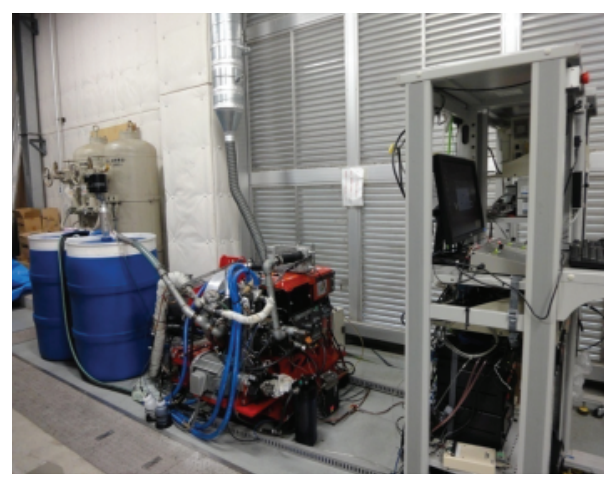

Figure 2: Diesel engine experimental device.

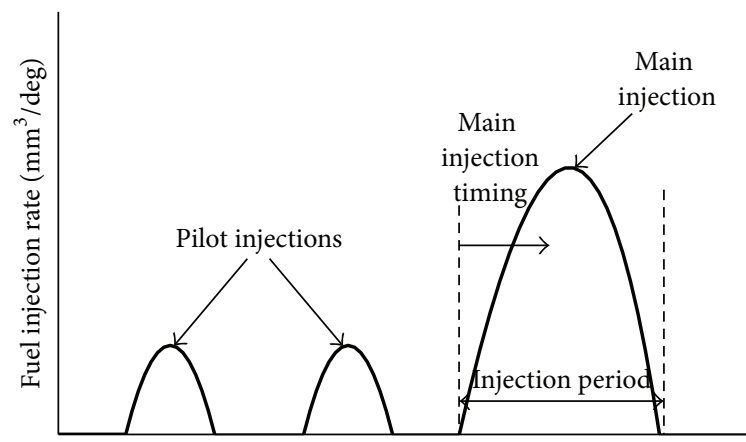

Injection timing (deg ATDC)

FIGURE 3: Multistage injection patterns.

for variables to be included or excluded. In this study, we use bidirectional elimination to identify the model.

Based on the experiment data, $x_{1}, x_{2}, x_{3}, x_{4}, x_{5}, x_{6}$, $x_{7}$, and $x_{8}$ as control parameters (input) and $y_{1}, y_{2}, y_{3}$, and $y_{4}$ represent the characteristic value of the optimization objective (output); we construct the polynomial model using stepwise method.

The model expresses the value of a response variable as a multilinear function of one or more predictor variables in order 1 and order 2 :

$$
y_{i}=\beta_{0}+\sum_{i=1}^{p} \beta_{i} x_{i}+\sum_{i<j}^{p} \beta_{i j} x_{i} x_{j}+\sum_{i=1}^{p} \beta_{i i} x_{i}^{2}+e_{i},
$$

TABLE 1: Specification of diesel engine.

\begin{tabular}{lc}
\hline Engine type & 4-cycle, 1 cylinder, and DI \\
\hline Bore $\times$ stroke & $78 \mathrm{~mm} \times 80 \mathrm{~mm}$ \\
Top clearance & $0.98 \mathrm{~mm}$ \\
Con-rod length & $115 \mathrm{~mm}$ \\
Compression ratio & 21.4 \\
Cylinder capacity & $0.382 \mathrm{~L}$ \\
Maximum output & $5.5 / 2600 \mathrm{~kW} / \mathrm{min}^{-1}$ \\
Full-length & $640 \mathrm{~mm}$ \\
Full-height & $474 \mathrm{~mm}$ \\
Full-width & $330.5 \mathrm{~mm}$ \\
\hline
\end{tabular}

where $y_{i}$ is response variable in observation $i, \beta_{0}$ is coefficient constant, $\beta_{i}$ is coefficient on the $x_{i}$ predictor, $\beta_{i j}$ is coefficient on the $x_{i}$ predictor and $x_{j}$ predictor, $\beta_{i i}$ is coefficient on the $x_{i}$ predictor 2 order, $p$ is the total number of predictors, and $e_{i}$ is error term. The model (1) is estimated by least squares method, which yields parameter estimates such that the sum of squares of errors is minimized. In order to select a clause effectively in presumption, we redefine one explaining variable about all the order 2 , respectively. For example, we redefine $u_{1}=x_{1}{ }^{2}$ and $u_{2}=x_{1} x_{2}$. Thus, the polynomial model selects the combination of an explaining variable effectively in presumption and constituted by the stepwise method. In this research, we use the multiple correlation coefficient $R$ that indicated the matching level of the calculation datum by the regression equation and the original datum; the result is better when $R$ is closer to 1 . Statistic values $F$ indicate the significance of the regression equation, whose values obey $F$ distribution.

4.2. The Stepwise Procedure with Consideration of Multicollinearity. The general procedure of the stepwise method consists of three steps. First, we select an initial regression model. Second, the procedure repeatedly alters the model by adding or removing a predictor variable in accordance with the F-test [12]. Finally, the search is terminated when the response variables which satisfy the stepping criterion do not exist anymore, or when the iteration step has reached 
TABLE 2: Diesel engine control parameters.

\begin{tabular}{llcc}
\hline Control parameter & Meaning & Unit & Variation range \\
\hline$x_{1}$ & Pilot 1 injection timing & deg. ATDC & $-60,-45$ \\
$x_{2}$ & Pilot 1 injection quantity & $\mathrm{mm}^{3} / \mathrm{st}$ & $0.1,0.2$ \\
$x_{3}$ & Pilot 2 injection timing & deg. ATDC & $-35,-25$ \\
$x_{4}$ & Pilot 2 injection quantity & $\mathrm{mm}^{3} / \mathrm{st}$ & $0.1,0.2$ \\
$x_{5}$ & Main injection timing & deg. ATDC & $-5,-4,-3,-2,-1$ \\
$x_{6}$ & Main injection quantity & $\mathrm{mm}^{3} / \mathrm{st}$ & $0.85,1$ \\
$x_{7}$ & Injection pressure & $\mathrm{MPa}$ & 85,100 \\
$x_{8}$ & Engine speed & $\mathrm{rpm}$ & $1000,1500,2000$ \\
\hline
\end{tabular}

TABLE 3: Optimization objectives.

\begin{tabular}{lcc}
\hline Optimization objective & Meaning & Unit \\
\hline$y_{1}$ & Power & $\mathrm{kW}$ \\
$y_{2}$ & $\mathrm{BSFC}$ & $\mathrm{g} / \mathrm{kWh}$ \\
$y_{3}$ & $\mathrm{NO}_{x}$ & $\mathrm{~g} / \mathrm{kWh}$ \\
$y_{4}$ & soot & $\mathrm{m}^{-1}$ \\
\hline
\end{tabular}

a specified maximum number. The flow chart of the stepwise model-building procedures is shown in Figure 4.

Multicollinearity is a term reserved to describe the case when the intercorrelation of predictor variables is high. Multicollinearity does not invalidate the regression model in the sense that the predictive value of the equation may still be good as long as the prediction is based on combinations of predictors within the same multivariate space used to calibrate the equation. But there are several negative effects of multicollinearity such as the variance of the regression coefficients which can be inflated so much that the individual coefficients are not statistically significant even though the overall regression equation is strong and the predictive ability is good.

The variance inflation factor (VIF) is a statistic that can be used to identify multicollinearity [13] in a matrix of predictor variables. Variance inflation refers here to the mentioned effect of multicollinearity on the variance of estimated regression coefficients. Multicollinearity depends not just on the bivariate correlations between pairs of predictors, but on the multivariate predictability of any one predictor from the other predictors as well. Accordingly, the VIF is based on the multiple correlation coefficients in regression of each predictor in multivariate regression on all the other predictors:

$$
\mathrm{VIF}=\frac{1}{1-R^{2}}
$$

\section{Particle Swarm Optimization}

PSO algorithm is an adaptive algorithm based on a socialpsychological metaphor; a population of individuals (referred to as particles) adapts by returning stochastically toward previously successful regions [14]. Particle swarm has two primary operators: velocity update and position update. During each generation, each particle is accelerated toward the particles previous best position and the global best position. For each iteration a new velocity value for each particle is calculated based on its current velocity, the distance from its previous best position, and the distance from the global best position. The new velocity value is then used to calculate the next position of the particle in the search space. This process is then iterated for a set number of times, or until a minimum error is achieved. The flow chart of particle swarm optimization algorithm is shown in Figure 5.

\section{Combustion Model Compilation in Microcontroller}

In this research, we want to compile the combustion model which added PSO result in microcontroller and install in diesel engine to do real experiment/validation in diesel engine. First, we have to create a Simulink model using MATLAB and Simulink. Instead of programming C code manually, we can implement the control algorithm graphically using Simulink blocks. The models are saved as MDL files. In this research we built combustion model with stepwise method and optimized by PSO. All of this work was done by Simulink and MATLAB. Finally, we get the comparison of validation result and the estimation result of an engine control parameter.

\section{Result and Discussion}

7.1. Estimation and Experiment Result of the Combustion Model. In this research, the number of experiment data used to create the model is 501 data and number of experiment data used to test the model is 111 data. Based on the stepwise method considering multicollinearity, the estimation and experiment result of the combustion model is as below. The estimated value and actual measurement of power by stepwise method without multicollinearity with 2 order polynomial equations are shown in Figure 6. The dotted line is experiment value and solid line is estimate value. The multiple correlation coefficient $R$ is 0.98009 but this model uses 17 variables and $F$ value is only 692.2417.

The estimate value and actual measurement of power by stepwise method considering multicollinearity with 2 order polynomial equations are shown in Figure 7. If compared with Figure 6, the multiple correlation coefficient $R$ is only 


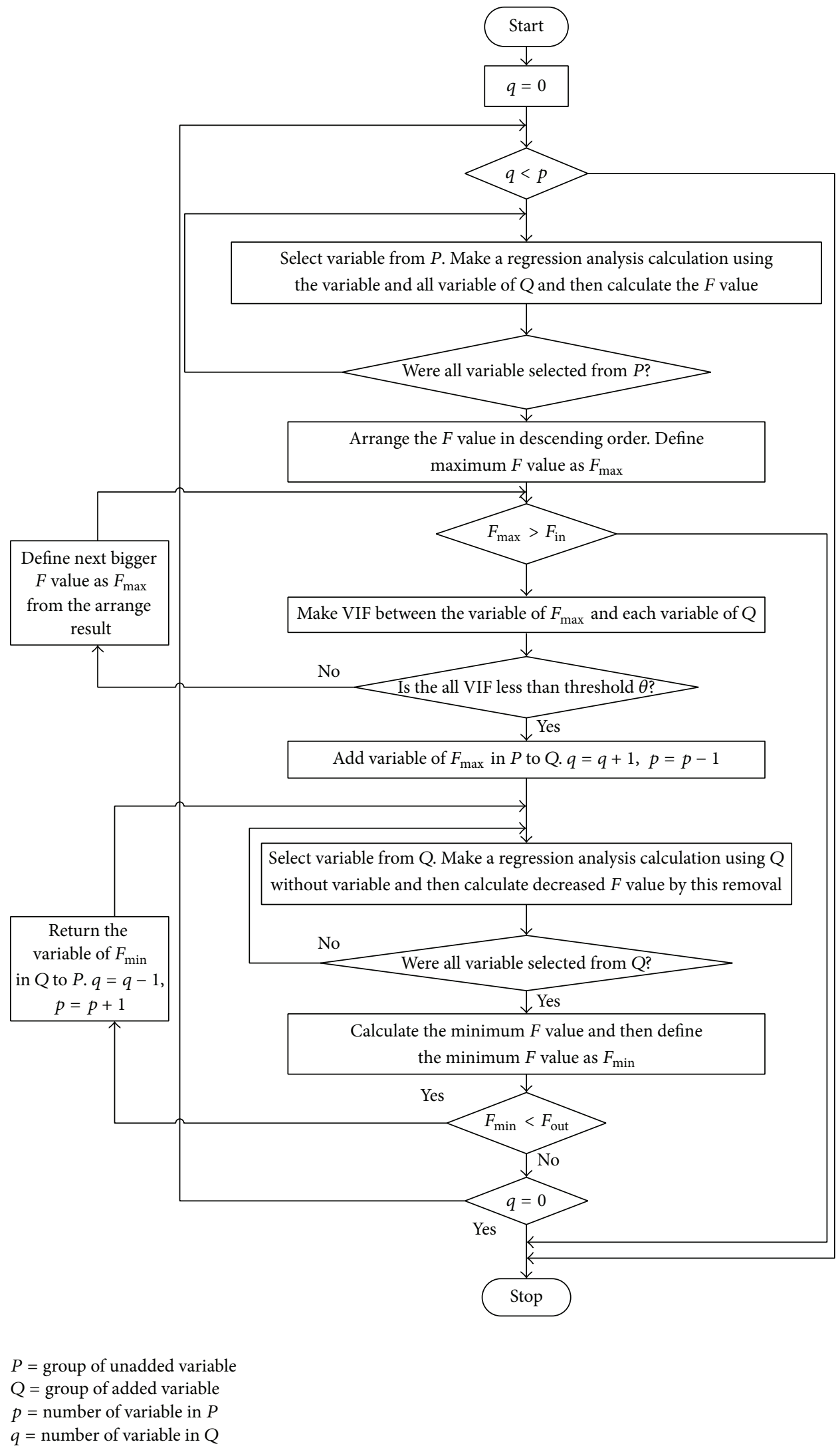

FIGURE 4: Model-building procedure of stepwise regression. 


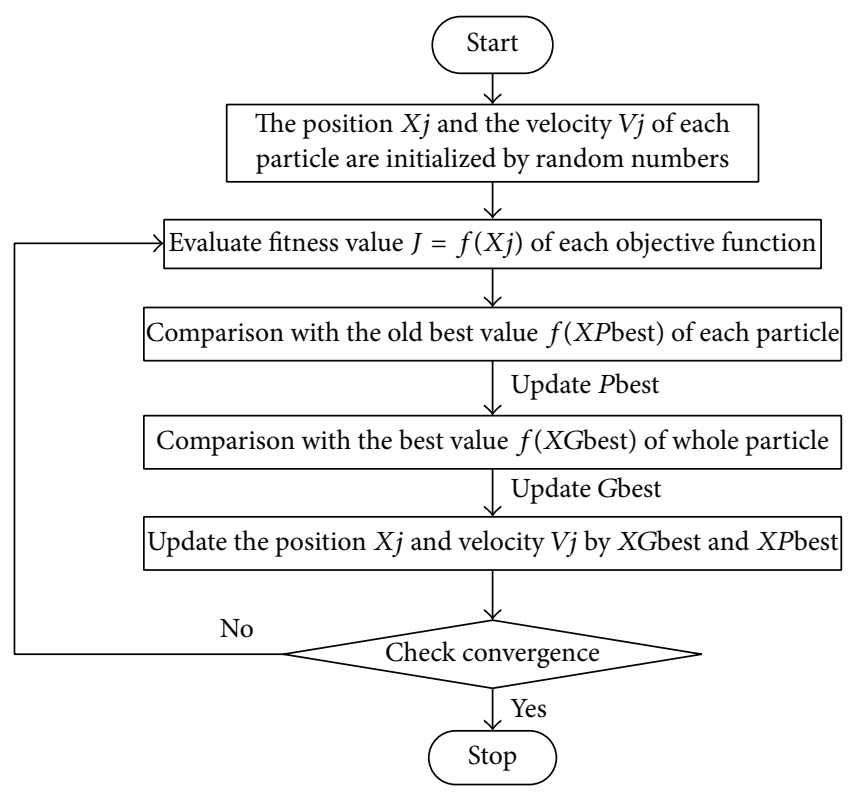

FIGURE 5: The flow chart of PSO algorithm.

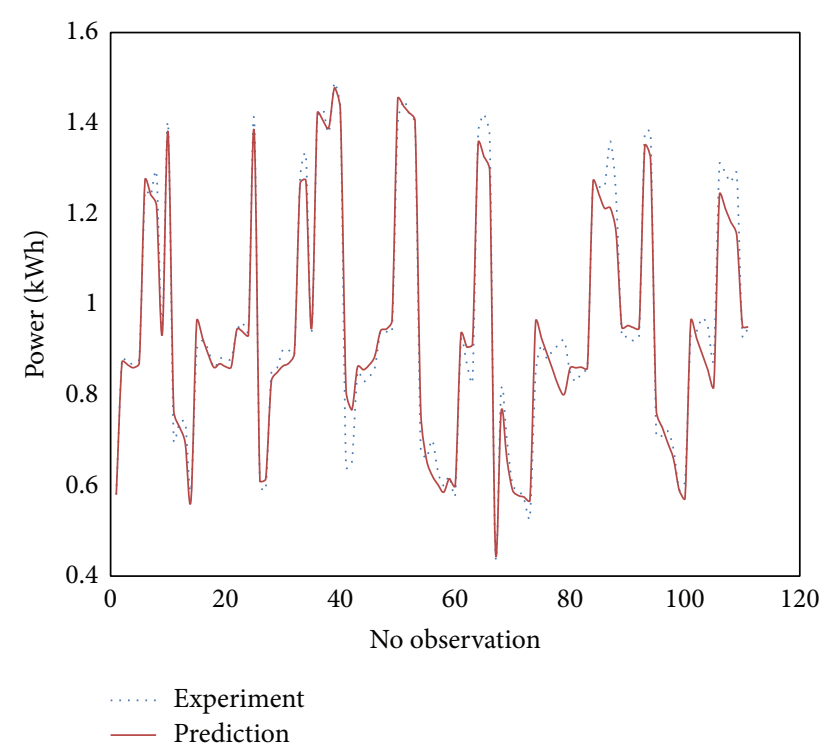

FIGURE 6: Estimate value based on stepwise without multicollinearity.

0.96794 but this model only uses 4 variables and $F$ value is higher, that is, 1841.4841. It shows higher accuracy. The combustion model of power constructed by stepwise method considering multicollinearity is

$$
\begin{aligned}
\text { Power }= & -1.2209+1.5953 e-001 x_{6}+2.1274 e-003 x_{6} x_{8} \\
& +6.7681 e-006 x_{7} x_{8}-7.7904 e-007 x_{8}{ }^{2} .
\end{aligned}
$$
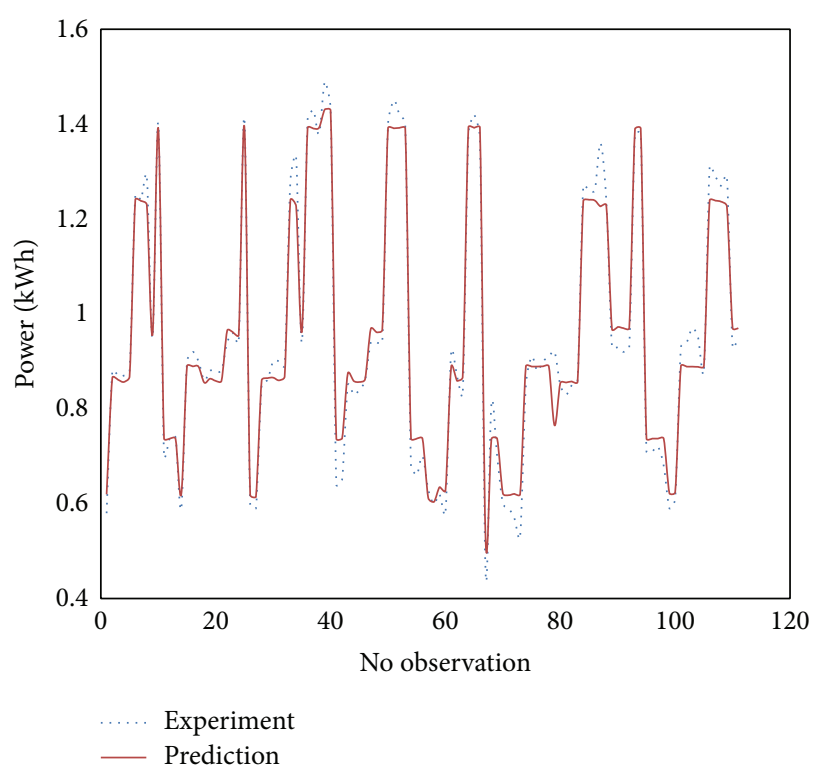

FIGURE 7: Estimate value based on stepwise considering multicollinearity.

In the same way we obtain the combustion model of BSFC, $\mathrm{NO}_{x}$, and soot constructed by stepwise method considering multicollinearity:

$$
\begin{aligned}
\mathrm{BSFC}= & 37.745-57.0318 x_{5}+4.9796 e-002 x_{5} x_{8} \\
& +11.3256 x_{6} x_{7}-5.8178 e-001 x_{6} x_{8} \\
& -7.1307 e-002 x_{7}{ }^{2}+3.2240 e-004 x_{8}{ }^{2} \\
& (R=0.91523 \text { and } 6 \text { variables }) \\
\mathrm{NO}_{x}= & 2420.4546+174.1355 x_{6}-1.8747 x_{8} \\
& +3.6476 e-002 x_{3}{ }^{2}-39.2817 x_{6} x_{7}+1.586 x_{6} x_{8} \\
& +1.6560 e-001 x_{7}{ }^{2}+2.9429 e-003 x_{7} x_{8} \\
& (R=0.95147 \text { and } 7 \text { variables }) \\
\text { Soot }= & -4.33+50.931 x_{2}+2.0626 e-003 x_{1}{ }^{2} \\
& +1.1329 x_{1} x_{2}+3.8892 e-004 x_{1} x_{3} \\
& +2.5323 e-003 x_{2} x_{3}-2.9668 e-004 x_{3}{ }^{2} \\
& (R=0.99603 \text { and } 6 \text { variables }) .
\end{aligned}
$$

In this research, we have reported our predicted model of power, BSFC, $\mathrm{NO}_{x}$, and soot in multiple injection diesel engines by stepwise method considering multicollinearity. It shows that the predictive accuracy by stepwise method considering multicollinearity is high. This is proved by the multiple correlation coefficient 0.9000 or more and $F$ value is very high. It can be regarded that the stepwise method can effectively estimate the objectives. 


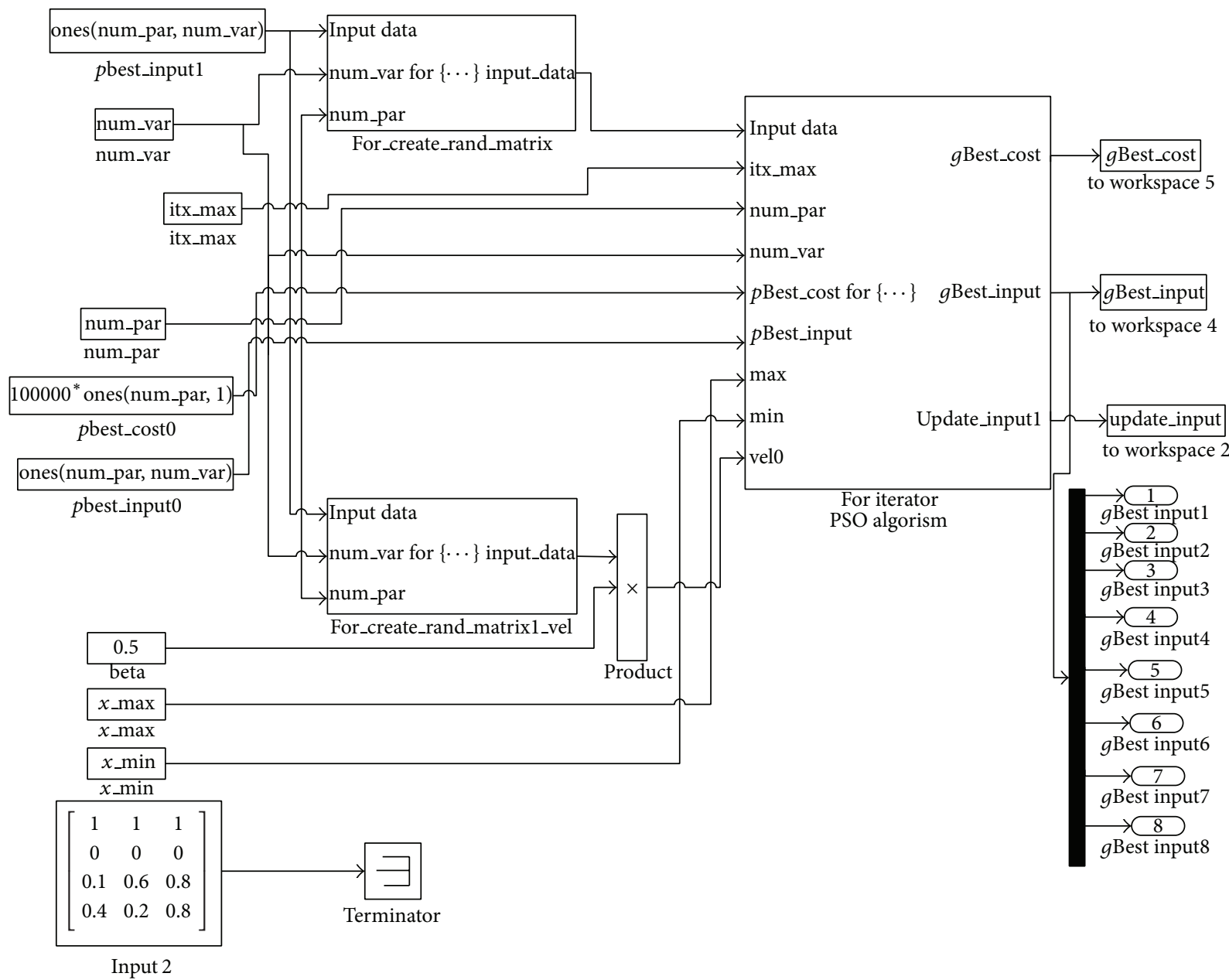

Figure 8: Combustion model with PSO.

In order to improve exhaust emissions and fuel efficiency in a diesel engine, in next step, we use particle swarm optimization (PSO), one of optimization techniques to find the optimal engine operating condition efficiently.

7.2. The Optimization of an Engine Control Parameter. Before getting the optimal value of engine control parameter, we have to create a Simulink model using MATLAB and Simulink. Instead of programming $\mathrm{C}$ code manually, we can implement the control algorithm graphically using Simulink blocks. The models are saved as MDL files. In this research we built combustion model with stepwise method and optimized by PSO. All of this work was done using Simulink and MATLAB. In Figure 8, we can see the combustion model with PSO built by Simulink.

Simulation with the PSO was repeated 10 times based on the engine speed (rpm) from $1000 \mathrm{rpm}$ to $2000 \mathrm{rpm}$, and 10 simulated engine optimal control parameters were obtained. The engine optimal control parameters are listed in Table 4.

7.3. Comparison of Validation Result and the Estimation Result of an Engine Control Parameter. The engine optimal control parameters were validated in an engine test bench, and the results of validation based on the simulated optimal control parameters were compared with the calculated engine optimal objective values. The experiment result as the validation result and the calculation result are shown in Figures 9, 10, 11, and 12.

The comparison of the experiment and the calculated engine optimal value of power, BSFC, $\mathrm{NO}_{x}$, and soot are illustrated in Figures 9-12, respectively. Based on Figures 912 , it is observed that the calculated optimal value of power is similar to the validated value from engine test bench. The validation optimal value of BSFC is similar to the calculated optimal value except in $1600 \mathrm{rpm}$ that increases $17.22 \%$. The validated optimal value of $\mathrm{NO}_{x}$ increases $13.77 \%$ in $1500 \mathrm{rpm}$ and $13.59 \%$ in $2000 \mathrm{rpm}$ but the validated optimal value of soot decrease $15.38 \%$ in $1300 \mathrm{rpm}$. Based on this result, the PSO method shows the effective methods in this optimization problem. Based on the observation in engine test bench, result of the optimization simulation, and the validation, conclusions for this study are the optimal control input parameters obtained by PSO were tested and analyzed. The result proved that the PSO is an effective method for engine optimization problem. 
TABLE 4: The engine optimal control parameters.

\begin{tabular}{lccccccccccc}
\hline \multirow{2}{*}{ Control parameter } & \multicolumn{1}{c}{ Engine speed (rpm) } \\
& 1000 & 1100 & 1200 & 1300 & 1400 & 1500 & 1600 & 1700 & 1800 & 1900 & 2000 \\
\hline$x_{1}$ & -45.47 & -45.62 & -45.61 & -45.17 & -45.75 & -45.40 & -45.31 & -45.27 & -45.61 & -45.75 & -45.40 \\
$x_{2}$ & 0.19 & 0.19 & 0.19 & 0.17 & 0.18 & 0.19 & 0.19 & 0.20 & 0.19 & 0.19 & 0.18 \\
$x_{3}$ & -25.30 & -25.30 & -25.15 & -25.77 & -25.73 & -25.68 & -25.98 & -25.69 & -25.33 & -26.46 & -25.25 \\
$x_{4}$ & 0.10 & 0.19 & 0.14 & 0.20 & 0.20 & 0.20 & 0.20 & 0.19 & 0.17 & 0.19 & 0.19 \\
$x_{5}$ & -1.06 & -4.79 & -4.99 & -4.73 & -4.63 & -4.69 & -4.65 & -4.93 & -4.60 & -4.81 & -4.75 \\
$x_{6}$ & 1 & 0.99 & 0.99 & 1 & 0.99 & 0.99 & 1 & 1 & 0.99 & 1 & 0.99 \\
$x_{7}$ & 98.91 & 99.55 & 98.86 & 99.73 & 98.83 & 99.61 & 99.08 & 98.66 & 99.29 & 99.94 & 99.69 \\
\hline
\end{tabular}

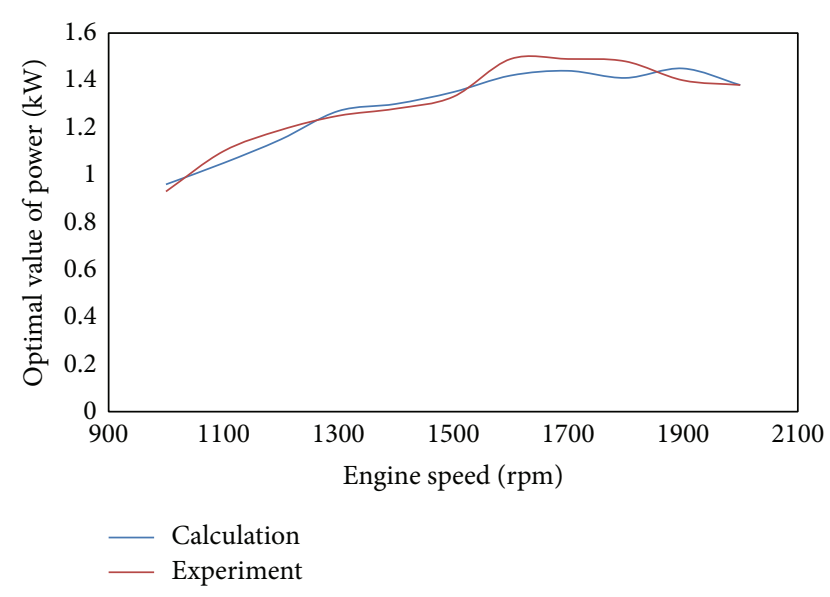

FIGURE 9: Comparison of estimation and calculation of optimal value of power.

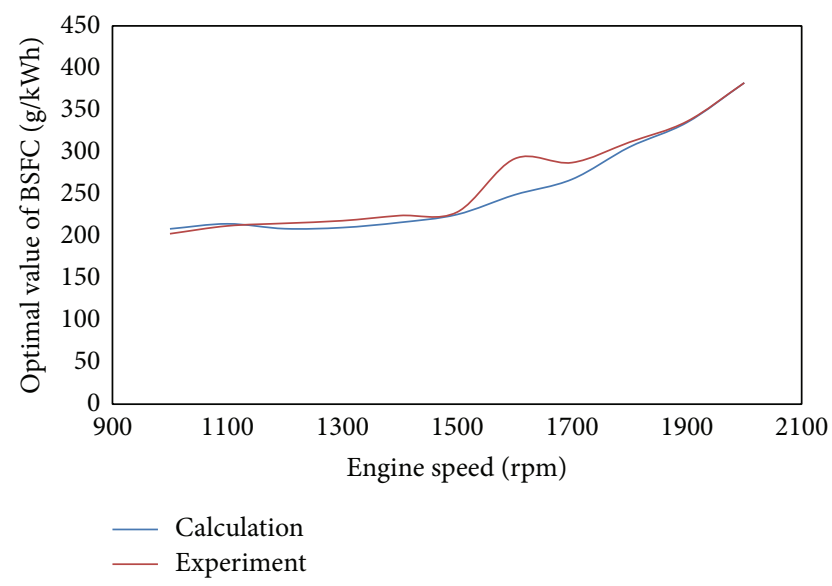

FIGURE 10: Comparison of estimation and calculation of optimal value of BSFC.

\section{Conclusions}

Based on the experiment data, in order to control the large number of control parameters appropriately in consideration of power, $\mathrm{BSFC}, \mathrm{NO}_{x}$, and soot as the engine output objectives, the model construction which reproduces the characteristic value of power, $\mathrm{BSFC}, \mathrm{NO}_{x}$, and soot from control parameter is needed. In this study, the stepwise method

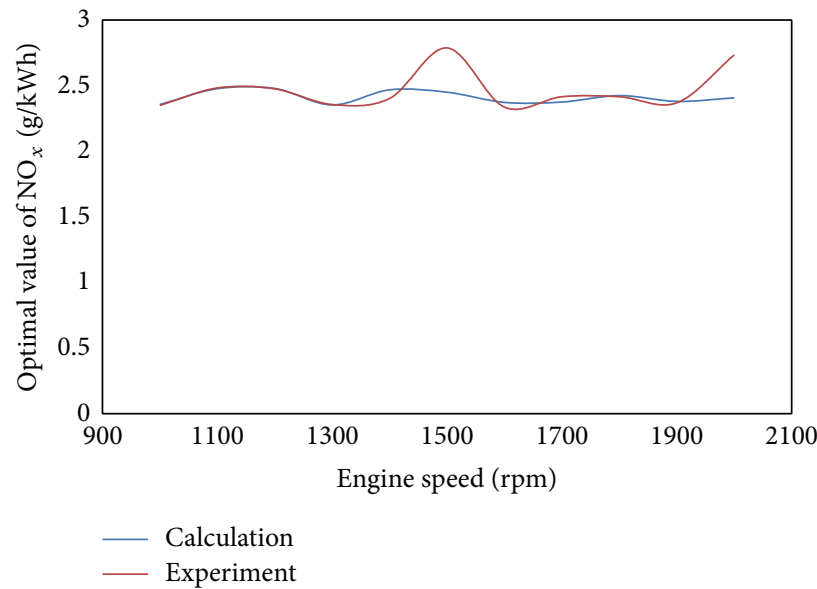

FIGURE 11: Comparison of estimation and calculation of optimal value of $\mathrm{NO}_{x}$.

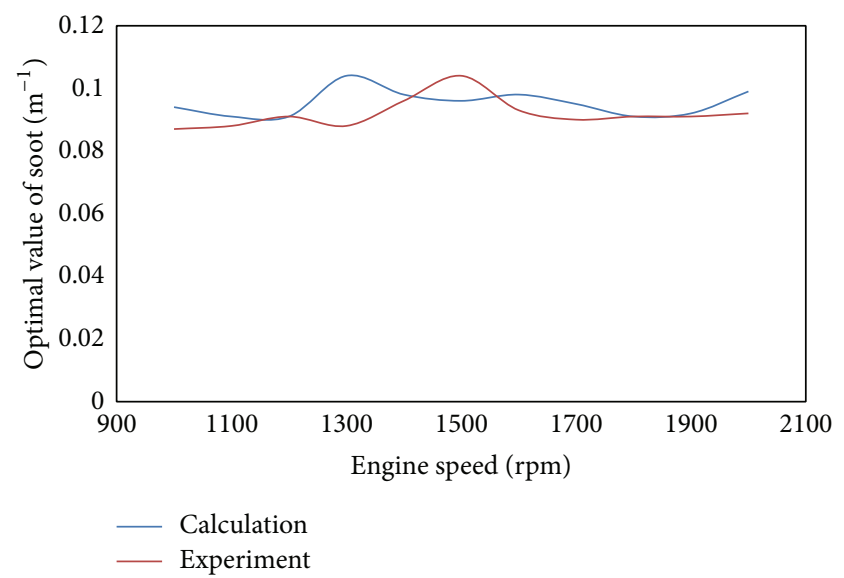

FIGURE 12: Comparison of estimation and calculation of optimal value of soot.

considering multicollinearity was applied to construct the polynomial model order 1 and order 2 .

The accuracy of predictions made using stepwise method models considering multicollinearity depends on how well the regression function fits the data; there should be regular checks to see how well a regression function fits a given data set. This can be done through regular updates to ensure 
that the error values are always below a prespecified error threshold.

In this research, we have reported our predicting model of power, $\mathrm{BSFC}, \mathrm{NO}_{x}$, and soot in multiple injection diesel engines by stepwise method considering multicollinearity. This paper shows that the predictive accuracy by stepwise method considering multicollinearity is high. This is proved by the multiple correlation coefficient 0.9000 or more and $F$ value is very high. It can be regarded that the stepwise method can effectively estimate the objectives.

In order to improve exhaust emissions and fuel efficiency in a diesel engine, we use particle swarm optimization (PSO), one of optimization techniques to find the optimal engine operating condition efficiently.

Based on the observation in engine test bench, result of the optimization simulation, and the validation, conclusions for this research are the optimal control input parameters obtained by PSO were tested and analyzed. The result proved that the PSO is an effective method for engine optimization problem.

\section{Conflict of Interests}

The authors declare that there is no conflict of interests regarding the publication of this paper.

\section{Acknowledgments}

This work was supported by INPEX Foundation, Japan. The authors would like to thank member of Diesel Engine Laboratory, Waseda University, for helping to get experiment data and their suggestion. Mr. Imam Sutrisno, Mr. Arifin Nur, and Mr. Zhong Lu are acknowledged for their support and productive discussion.

\section{References}

[1] NN, Stakeholder Dialogue on Improving Motor Vehicle Inspection and Maintenance Systems in Indonesia, 2013, http://www .kpbb.org/news/TOR\%20Workshop,\%207\%20March\%202013\% 20\%28Thursday\%29,.pdf.

[2] T. Kitamura, T. Ito, J. Senda, and H. Fujimoto, "Mechanism of smokeless diesel combustion with oxygenated fuels based on the dependence of the equivalence ratio and temperature on soot particle formation," International Journal of Engine Research, vol. 3, pp. 223-248, 2002.

[3] J. B. Heywood, Internal Combustion Engine Fundamentals, McGraw-Hill, New York, NY, USA, 1988.

[4] J. E. Dec, "A conceptual model of DI diesel combustion based on laser sheet imaging," SAE Technical Paper 970873, 1997.

[5] NN, “Emission Standard Japan,” 2013, http://www.dieselnet.com/ standards/jp/.

[6] N. Ladommatos, S. M. Abdelhalim, and H. Zhao, "The effects of exhaust gas recirculation on diesel combustion and emissions," International Journal of Engine Research, vol. 1, no. 1, pp. 107-126, 2000.

[7] P. C. Miles, D. Choi, L. M. Pickett et al., "Rate-limiting processes in late-injection, low-temperature diesel combustion regimes," in Proceedings of the International Conference on Thermo-and
Fluid Dynamic processes in Direct Injection Engines (THIESEL '04), vol. 429, 2004.

[8] P. Karra and S.-C. Kong, "Diesel emission characteristics using high injection pressure with converging nozzles in a mediumduty engine," SAE International Journal of Fuels and Lubricants, vol. 1, no. 1, pp. 578-592, 2009.

[9] Z. Lu, M. Ogawa, and H. Ogai, "Response Surface Modeling of Multiple Injection Diesel Engine," in Proceedings of the 54th Conference of the Automatic Control Federation, Toyohashi University of Technology, November 2011.

[10] W. L. Hardy and R. D. Reitz, "An experimental investigation of partially premixed combustion strategies using multiple injections in a heavy-duty diesel engine," SAE Technical Paper 2006-01-0917, 2006.

[11] N. Zhou, Z. Huang, F. Tuffner, D. Trudnowski, and W. Mittelstadt, "A modified stepwise linear regression method for estimating modal sensitivity," in Proceedings of the IEEE Power and Energy Society General Meeting, pp. 1-7, July 2011.

[12] A. C. Rencher, Methods of Multivariate Analysis, Wiley Series in Probability and Statistics, Wiley-Interscience, New York, NY, USA, 2nd edition, 2002.

[13] J. O. Rawlings, S. G. Pantula, and D. A. Dickey, Applied Regression Analysis: A Research Tool, Springer, New York, NY, USA, 2nd edition, 1998.

[14] J. Kennedy and R. Eberhart, Swarm Intelligence, Morgan Kaufmann Publishers, San Francisco, Calif, USA, 2001. 


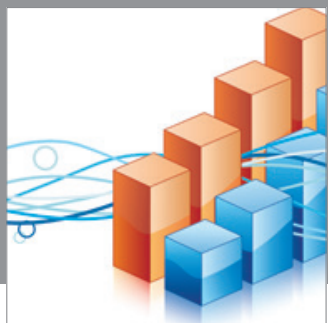

Advances in

Operations Research

mansans

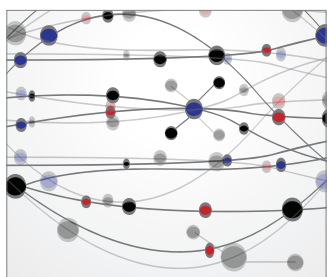

The Scientific World Journal
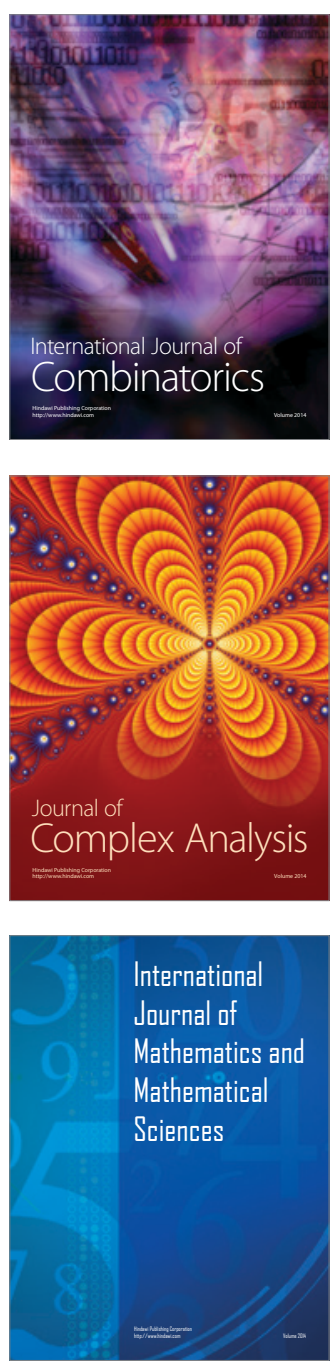
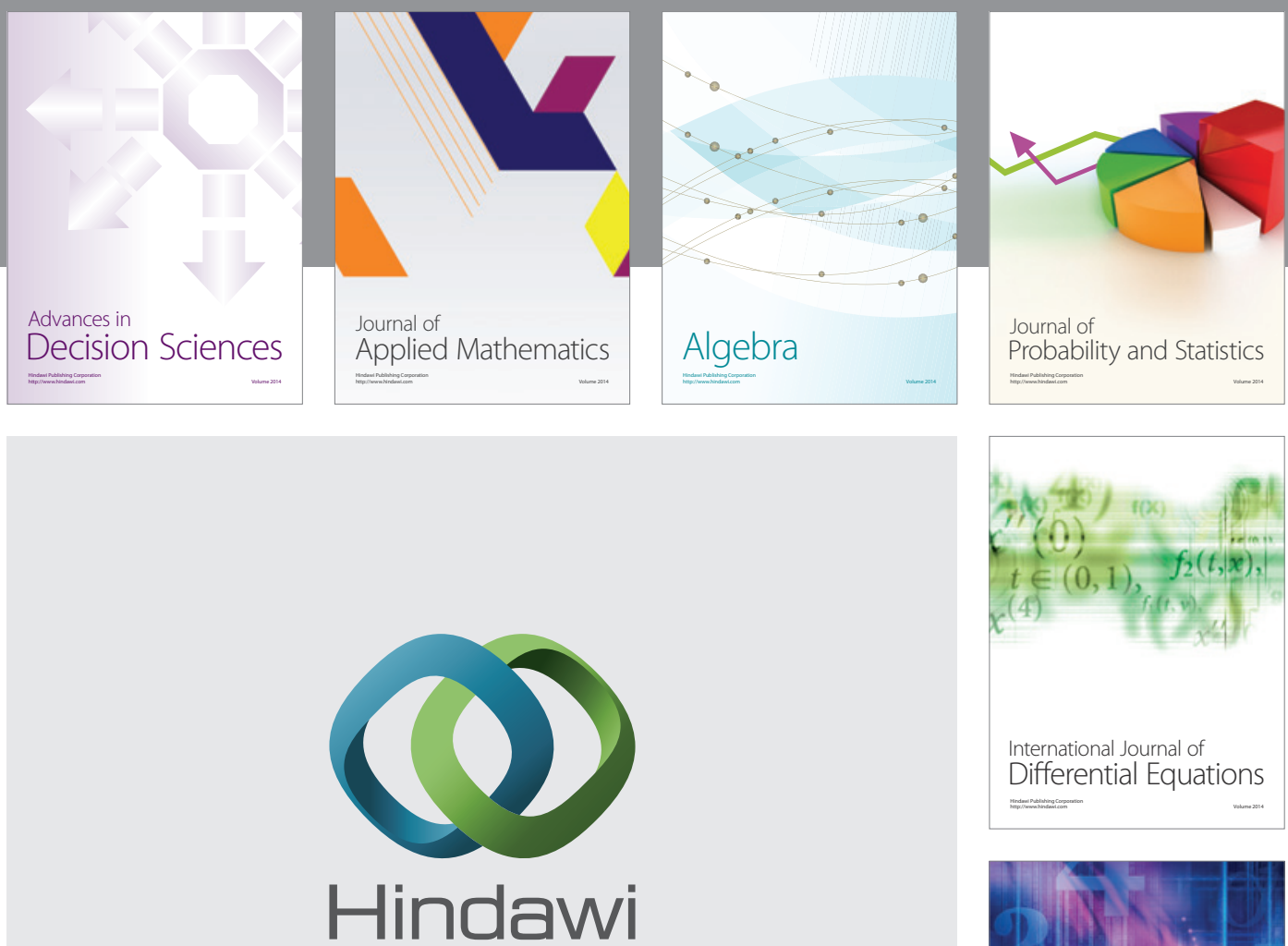

Submit your manuscripts at http://www.hindawi.com
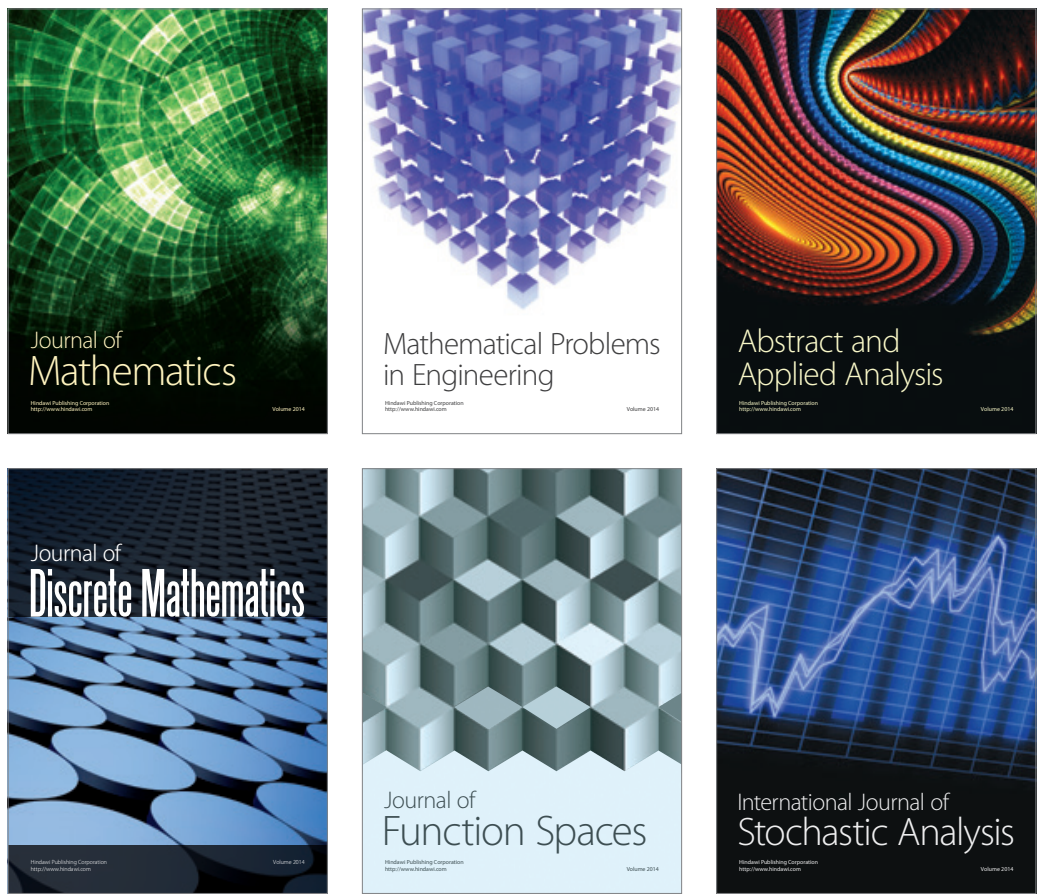

Journal of

Function Spaces

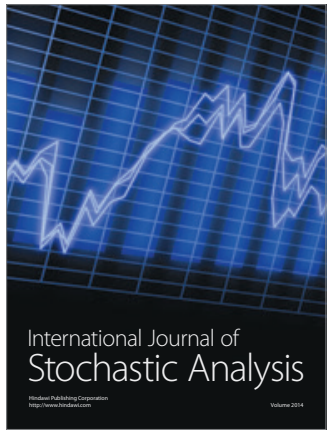

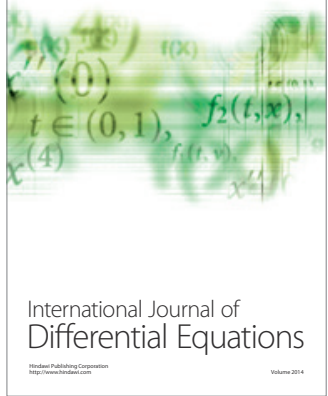
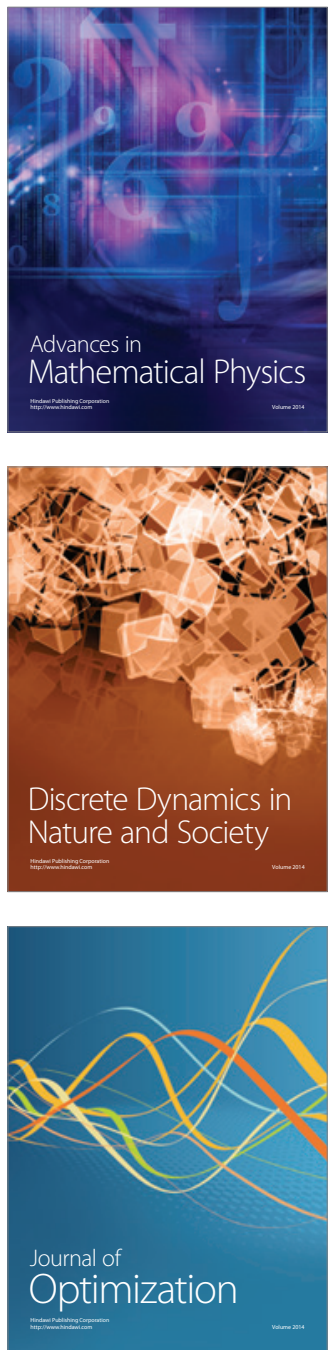